\title{
Correction to: DNAJC12 deficiency in patients with unexplained hyperphenylalaninemia: two new patients and a novel variant
}

\author{
Kısmet Çıkı ${ }^{1}$ Yıımaz Yıldız ${ }^{1}$. Didem Yücel Yılmaz ${ }^{2} \cdot$ Emine Pektaşs $^{3} \cdot$ Ayşegül Tokatlı $^{1} \cdot$ R. Köksal Özgül ${ }^{2}$. \\ H. Serap Sivri ${ }^{1} \cdot$ Ali Dursun $^{1}$
}

Published online: 9 June 2021

๑) Springer Science+Business Media, LLC, part of Springer Nature 2021

\section{Correction to: Metabolic Brain Disease}

https://doi.org/10.1007/s11011-021-00753-0

The title "DNACJ12 deficiency in patients with unexplained hyperphenylalaninemia: two new patients and a novel variant" should be "DNAJC12 deficiency in patients with unexplained hyperphenylalaninemia: two new patients and a novel variant"

Publisher's note Springer Nature remains neutral with regard to jurisdictional claims in published maps and institutional affiliations.

The original article can be found online at https://doi.org/10.1007/ s11011-021-00753-0.

Kısmet Çıkı

kismet.ciki@hacettepe.edu.tr

1 Division of Pediatric Metabolism, Department of Pediatrics, Faculty of Medicine, Hacettepe University, Ankara, Turkey

2 Department of Pediatric Metabolism, Institute of Child Health, Hacettepe University, Ankara, Turkey

3 Pediatric Metabolic Diseases Unit, Gaziantep Cengiz Gökçek Maternity and Pediatrics Hospital, Gaziantep, Turkey 